\title{
An approach to the solitary pulmonary nodule
}

\author{
S Abraham, MB ChB, MMed (Int), FCP (SA); M J Vorster, MB ChB, MRCP (UK), MMed (Int), FCP (SA); \\ S S Roy, MBBS, DTCD, MD (Internal Medicine), FCCP; \\ C F N Koegelenberg, MB ChB, MMed (Int), FCP (SA), FRCP (UK), Cert Pulmonology (SA), PhD
}

Division of Pulmonology, Department of Medicine, Faculty of Medicine and Health Sciences, Stellenbosch University and Tygerberg Hospital, Cape Town, South Africa

Corresponding author: S Abraham (shinu_29@yahoo.com)

\begin{abstract}
Solitary pulmonary nodules may represent early lung cancer, which is potentially curable. The advent of improved imaging techniques, together with the worldwide implementation of screening programmes, has intensified the need for a structured approach to the management of pulmonary nodules. We present an overview of the current literature on risk stratification, characteristics and management of pulmonary nodules that are relevant to practitioners in South Africa.
\end{abstract}

S Afr Respir J 2016;22(3):54-60. DOI:10.7196/SARJ.2016.v22i3.83

In clinical practice, solitary pulmonary nodules (SPNs) represent a common challenge, as they may be indicative of early cancer that is curable; however, after extensive investigation the vast majority are found to be of benign aetiology. While advanced lung cancer survival rates remain low $-17 \%$ at 5 years - the diagnosis of early lung cancer (stage $1 \mathrm{~A}$ ) can be associated with a 5 -year survival rate of $70-80 \%{ }^{[1]}$ The best possibility for cure in potentially malignant SPNs is prompt diagnosis and surgery, while at the same time trying to avoid unnecessary intervention and surgery in patients with benign disease processes. ${ }^{[2]}$

Traditionally an SPN is defined as a single, usually wellcircumscribed spherical opacity of $\leq 3 \mathrm{~cm}$, completely surrounded by pulmonary parenchyma and not associated with lymphadenopathy, atelectasis or pleural effusion. ${ }^{[3]}$ The new British Thoracic Society (BTS) guideline $\mathrm{e}^{[4]}$ extends the definition to include nodules in contact with the pleura. Most SPNs are asymptomatic and discovered incidentally. The incidence of SPNs ranges from $0.2 \%$ in older radiographic studies to $40-60 \%$ in lung screening studies. ${ }^{[2]}$ Lesions $>3 \mathrm{~cm}$ are considered as masses and have a high likelihood of malignancy, requiring prompt diagnosis and management.

The differential diagnosis of SPNs (Table 1) is broad, with a variety of aetiologies, which include malignancies such as bronchogenic carcinoma, carcinoid tumours, lymphoma, and solitary pulmonary metastasis, and benign aetiologies such as granulomas and hamartomas ${ }^{[2]}$ - the most common benign causes.

\section{Low-dose computed tomography screening}

With the increasing use of computed tomography (CT) of the chest, the detection of SPNs has become common. ${ }^{[5]}$ The implementation of low-dose CT lung cancer screening is expected to increase the detection of SPNs. Several studies, including lung screening trials in smokers, suggest that the majority of nodules identified on CT are benign. ${ }^{[2,6-10]}$ In the Pan-Canadian Early Detection of Lung Cancer and the British Columbia Cancer Agency studies, among the 7008 and 5021 nodules detected, respectively, only a total of 144 (1\%) were malignant. ${ }^{[7]}$ The false-positive rate in the National Lung Screening Trial (NLST) was $96 \%{ }^{[10]}$

\section{General evaluation of an SPN}

The assessment of an SPN involves risk stratification of the individual patient, performing further imaging studies (if available), and formulating a management plan after taking into consideration the risks associated with various treatment strategies and individual patient preferences.

\section{Risk stratification}

Principles

Estimation of the pretest probability of cancer in an SPN includes clinical assessment of individual risk, evaluation of radiological features to differentiate between benign and malignant nodules, and use of models using logistic regression. Logistic regression models use both clinical and radiological parameters to assess the pretest risk of malignancy. This risk assessment determines further management steps, which may include CT surveillance, further investigation (e.g. positron emission tomography (PET)-CT) and/ or biopsy (non-surgical or surgical).

\section{Clinical assessment}

Clinical risk stratification considers individual demographics and medical history and assesses the patient's risk. Risk factors associated with a higher likelihood of malignancy include advanced age, current or ever smokers, time from smoking cessation, number of pack-years, emphysema, asbestos exposure, history of previous extrapulmonary malignancy, radiation therapy, idiopathic pulmonary fibrosis and $\mathrm{HIV}^{[2,4]}$

\section{Chest radiography}

SPNs (Fig. 1) are still commonly first detected on chest radiographs, and a diameter of $8-10 \mathrm{~mm}$ is usually required before they are visible. Certain patterns of calcification may point to a benign cause (discussed below). 
Table 1. The differential diagnosis of a solitary pulmonary nodule

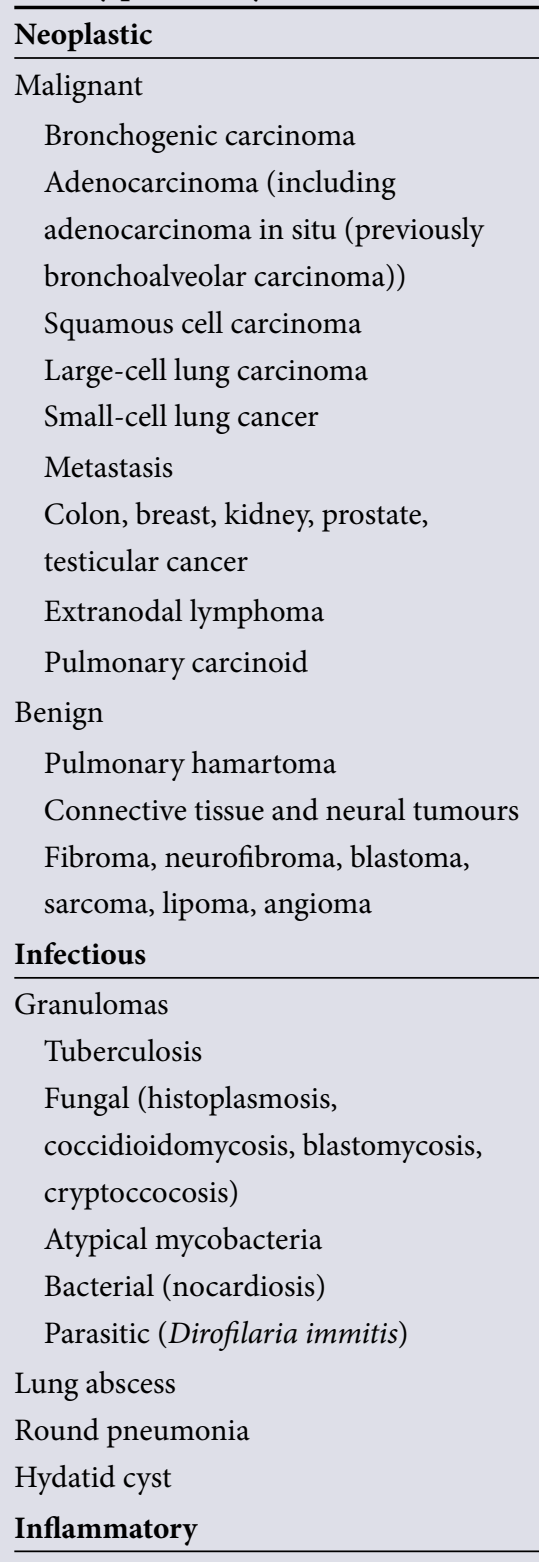

Rheumatoid arthritis

Sarcoidosis

Granulomatosis with polyangitis

Lipoid pneumonia

\section{Congenital}

Pulmonary sequestration

Bronchogenic cyst

Arteriovenous malformation

\section{Miscellaneous}

Pulmonary infarct

Rounded atelectasis

Mucoid impaction

Progressive massive fibrosis

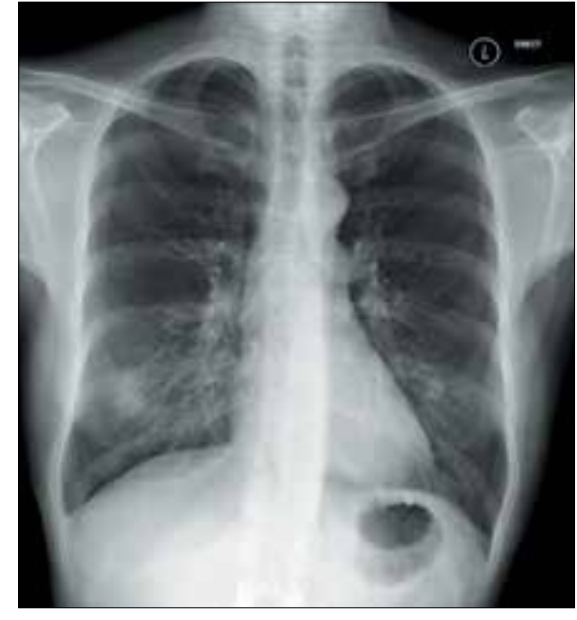

Fig. 1. An example of an SPN seen on chest radiography. A nodule was noted in the right lower zone of a 50-year-old female smoker. A $C T$ and an integrated PET-CT were done on the patient (Figs 2 and 4).

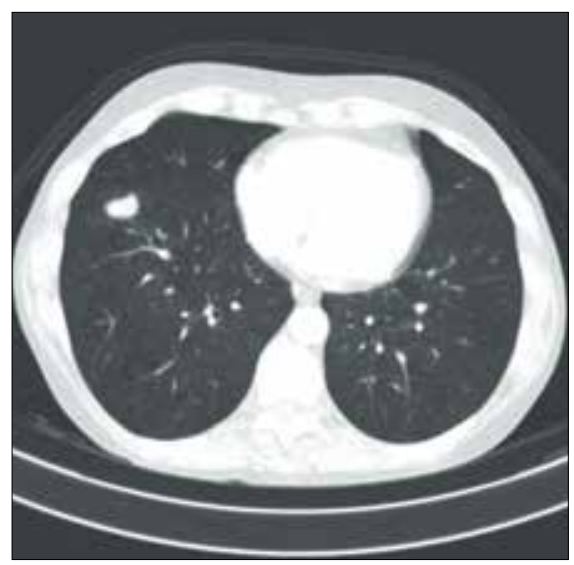

Fig. 2. A CT scan of the chest of the same patient as in Fig. 1, showing a $19 \times 12 \mathrm{~mm}$ $S P N$ in the right lower lobe.

\section{Chest CT}

In a patient with an indeterminate nodule identified by chest radiography, it is recommended that CT of the chest should be performed (preferably with thin sections through the nodule). The predictors on CT (Fig. 2) that could assist with the likelihood of malignancy in SPNs include: the nodule size, border, density (calcification, fat), growth rate or volume-doubling time (VDT), nodule attenuation and location.

Data from clinical trials indicate that the risk of malignancy rises with increasing nodule size. ${ }^{[6,7,11,12]}$ More than $90 \%$ of nodules $<2 \mathrm{~cm}$ in diameter are benign. However, subcentimeter nodules may represent an early stage of lung cancer. Data from the NLST suggested that the likelihood of malignancy increased significantly from $1.7 \%$ for nodules $7-10 \mathrm{~mm}$ in diameter to $11.9 \%, 29.7 \%$ and $41.3 \%$ for nodules with a diameter of $11-20 \mathrm{~mm}, 21$ $30 \mathrm{~mm}$ and $>30 \mathrm{~mm}$, respectively. ${ }^{[10]}$

Nodules with irregular, lobulated or spiculated (corona radiata) borders are associated with a progressively higher probability of malignancy than those with smooth borders. ${ }^{[6,13]}$ The corona radiata sign consists of very fine linear strands extending 4 - $5 \mathrm{~mm}$ outward from the nodule. Nevertheless, malignant SPNs may also present with a smooth border.

Certain types of calcification in SPNs indicate benign disease processes. There are six different patterns of calcification: central dense nidus; diffuse solid; laminated; popcorn; punctate; and dendriform. ${ }^{[14]}$ Diffuse, central, laminated and popcorn calcification are considered to be benign ${ }^{[3,4,13,15,16]}$ - the first three types are associated with granulomatous processes, with popcorn calcification typically occurring in a pulmonary hamartoma. The presence of intranodal fat density and popcorn calcification is specific for pulmonary hamartoma. All other patterns of calcification are suspicious of malignancy. Stippled and eccentric calcification patterns are seen in malignant nodules and warrant further evaluation and workup. ${ }^{[17]}$

Lung nodules containing fat include pulmonary hamartoma, lipoma and lipoid pneumonia.

Calcific metastases may occur in primary sarcomas, such as osteosarcoma, chondrosarcoma and synovial sarcoma. ${ }^{[14]}$ Primary carcinomas associated with metastases that may calcify include papillary and mucinous adenocarcinomas, and medullary carcinoma of the thyroid. ${ }^{[14]}$

Studies have shown that $70 \%$ of lung cancers are located in the upper lobes. ${ }^{[4,6,7]}$ As benign nodules can occur in the upper and lower lobes, location is not a good independent predictor of malignancy. Tuberculosis (TB) is common in the South African (SA) setting and classically affects the upper lobes. Perifissural and subpleural solid nodules are likely to be benign if they are homogeneous, have a lentiform or triangular shape, measure $<10 \mathrm{~mm}$ in size, and are within $1 \mathrm{~cm}$ of the fissure or the pleural surface. ${ }^{[18]}$

Based on nodule attenuation on CT, SPNs can be classified as non-solid (ground glass), partly solid, or solid. Non-solid nodules have underlying bronchovascular structures visible 
through them, while a partly solid nodule also contains solid regions that will mask visibility of the underlying bronchovascular structures. ${ }^{[19]}$ New nomenclature for SPNs has been adopted by the BTS guideline, ${ }^{[4]}$ with classification of nodules into solid and subsolid; additionally, there is subclassification of subsolid nodules into part-solid and pure ground-glass nodules (pGGNs) (Fig. 3).

Solid lesions are more common in practice, but subsolid lesions have a higher likelihood of being malignant, with CT screening studies showing that the identification of a solid component in a partly solid nodule was an independent predictor of malignancy. ${ }^{[20]}$ Pure ground-glass SPNs typically represent adenocarcinoma in situ, atypical adenomatous hyperplasia or minimally invasive adenocarcinoma. ${ }^{[4]}$ Increased growth or development of a solid component in a GGN is strongly associated with transformation to invasive adenocarcinoma. ${ }^{[2]}$

The VDT for malignant bronchogenic tumours is rarely $<1$ month or $>1$ year. ${ }^{[21]}$ The average doubling time for a malignant tumour is 120 days (range 7 - 590 days). The exception would be indolent tumours, such as adenocarcinoma in situ, which has a doubling time of up to 900 days. Doubling times $<1$ month may indicate infection, infarction, a lymphoma, or fast-growing metastases. ${ }^{[22,23]}$

Data from the Dutch-Belgian Randomized Lung Cancer Screening Trial (Dutch acronym: NELSON) found that VDT in SPNs $<400$ days, $400-600$ days, and $>600$ days at 3- and 12-month screening had 2-year cancer probabilities of $9.7 \%, 4.1 \%$ and $0.8 \%$ respectively. ${ }^{[24]}$

Other characteristics suggestive of malignancy on CT include: vascular convergence, dilated bronchus leading to the nodule, presence of pseudocavitation or true cavitation. ${ }^{[16]}$ Benign lesions usually have thinner, smoother walls $<4 \mathrm{~mm}$, thicker irregular walls $>15 \mathrm{~mm}$ being suggestive of malignancy. ${ }^{[19,25,26]}$ Nevertheless, there is overlap between the two, with thick-walled cavities also seen in benign infectious processes such as $\mathrm{TB}$, fungal infections and rheumatoid nodules. ${ }^{[27]}$

Pretest probability testing with a logistic model There are various validated prediction models that use a combination of clinical and radiological features to assess the probability

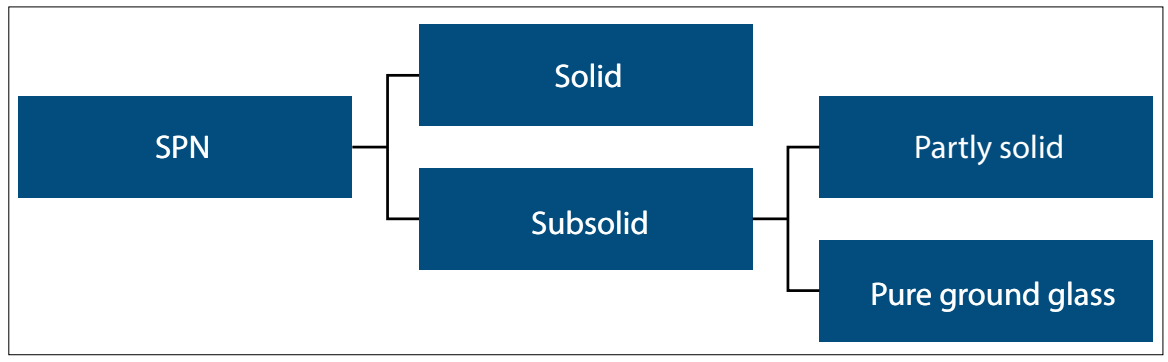

Fig. 3. A general classification of SPNs.

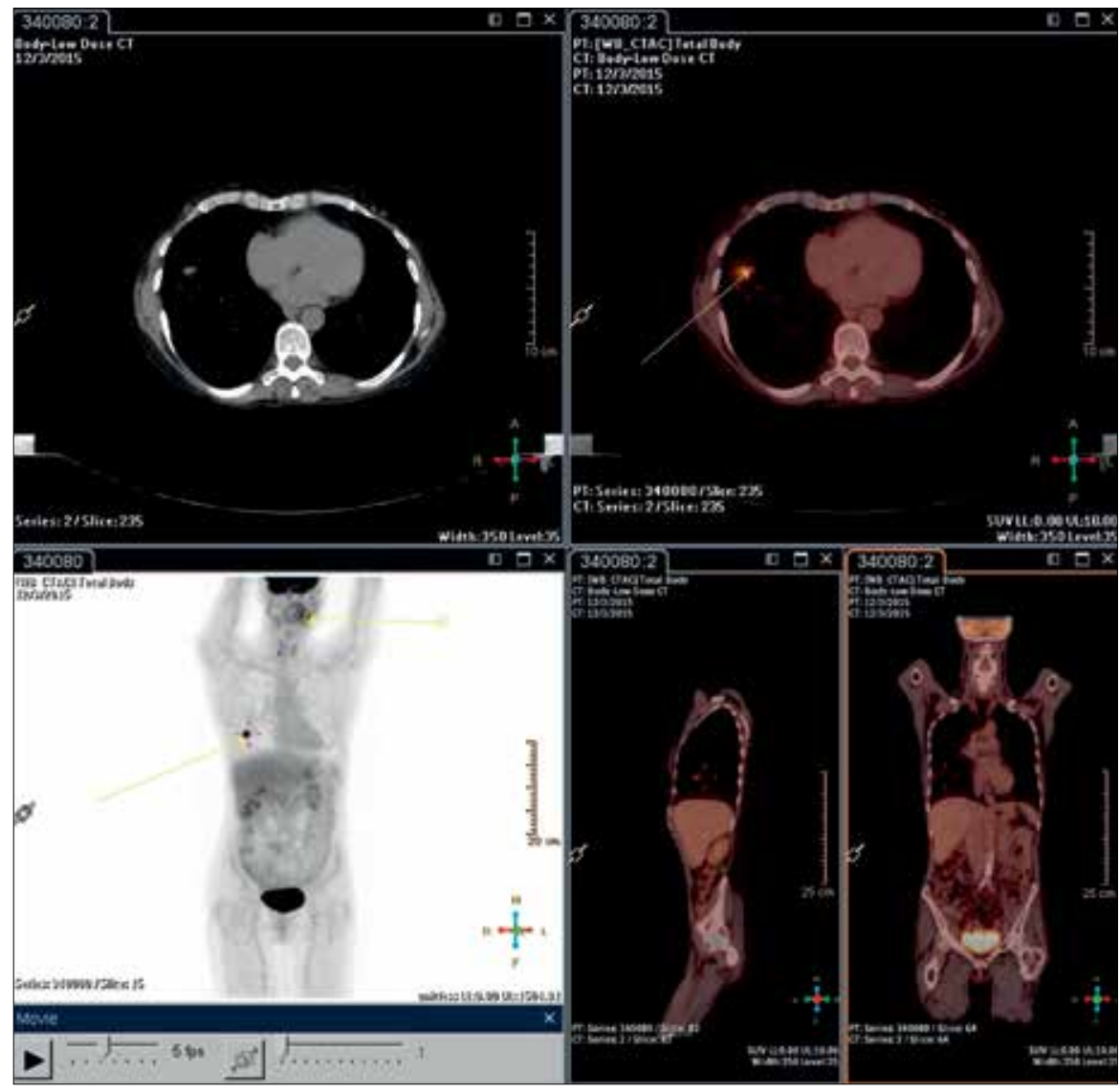

Fig. 4. The corresponding PET-CT of the patient in Fig. 2, showing a mass with FDG uptake. The standardised uptake value was 7.06. A surgical biopsy was done, which revealed a poorly differentiated neuro-endocrine tumour.

of malignancy. Prediction calculators are available online and also via medical applications for downloading on mobile devices. Current guidelines recommend their use in risk assessment. ${ }^{[4,16]}$ The newest of these guidelines is the BTS guideline (2015), which recommends the use of the Brock and Herder models in its management algorithms.

The Bayesian model ${ }^{[12]}$ uses the most important predictors of malignancy, i.e. spiculation, diameter and cavity wall thickness. Predictors of a benign aetiology are VDT $>465$ days and calcification. The Mayo Clinic model ${ }^{[6]}$ uses six independent predictors of malignancy, including three clinical risk factors (age, smoking status, history of cancer $>5$ years previously), and three radiological features (diameter, spiculation and upper-lobe location). The Veterans Administration model ${ }^{[11]}$ uses independent predictors of positive smoking history, older age, larger nodule diameter and time since quitting smoking. The Brock University model ${ }^{[7]}$ is based on the predictors of cancer, including older age, female sex, family history of lung cancer, emphysema, larger nodule size, location of the nodule in the upper lobe, SPN type, lower nodule count 
and spiculation. Lastly, the Herder model ${ }^{[28]}$ uses the addition of PET-CT and a 4-point intensity score to the Mayo Clinic model to improve its accuracy.

\section{Functional imaging and PET-CT}

Various functional imaging modalities have been studied in patients with SPNs to distinguish malignant from benign nodules. These include PET-CT, dynamic CT, dynamic magnetic resonance imaging (MRI) and dynamic single photon emission CT (SPECT). Studies have shown similar sensitivities between these different modalities for the detection of malignancy. ${ }^{[29]}$

18-Fluorodeoxyglucose (FDG) PET-CT is, however, the preferred functional imaging modality, as it is more widely available and assists in clinical lung cancer staging (Fig. 4).

False-positive PET findings with standard uptake values $>2.5$ are often seen in infectious or inflammatory conditions, including $\mathrm{TB}$, endemic mycoses (histoplasmosis), rheumatoid nodules, sarcoidosis and pneumonia. ${ }^{[30-32]}$ False-negative results are seen in subcentimeter $(<1 \mathrm{~cm})$ nodules, subsolid nodules, malignancies with low metabolic activity (e.g. adenocarcinoma in situ, carcinoid) and hyperglycaemia. ${ }^{[33]}$ Falsenegative results in the first three reflect the low mass of metabolically active malignant cells.

\section{Biomarkers}

Although some biomarkers have shown early interesting results, none has been validated for clinical use and none is currently recommended for use. ${ }^{[4]}$

\section{General management of SPNs}

Principles

Most guideline recommendations on the evaluation and management of SPNs are based on low-quality evidence and expert opinion. Two of these guidelines include those by the Fleischner Society (Table 2) ${ }^{[34,35]}$ and the American College of Chest Physicians (ACCP). ${ }^{[16]}$ These guidelines use nodule size to determine further management, based on patient risk stratification. The ACCP guideline has similar recommendations as the Fleischner Society, pertaining to nodule size and further management (no follow-up, CT surveillance or biopsy). The ACCP guideline,

Table 2. Recommendations for the management of SPNs as per statements from the Fleischner Society ${ }^{[34,35]}$

\begin{tabular}{|c|c|c|}
\hline Nodule type and size & Low risk & High risk \\
\hline \multicolumn{3}{|l|}{ Solid nodules } \\
\hline$\leq 4 \mathrm{~mm}$ & No follow-up & $\begin{array}{l}\text { Follow-up at } 12 \text { months; if } \\
\text { unchanged, no further follow-up }\end{array}$ \\
\hline$>4-6 \mathrm{~mm}$ & $\begin{array}{l}\text { Follow-up at } 12 \text { months; if } \\
\text { unchanged, no further } \\
\text { follow-up }\end{array}$ & $\begin{array}{l}\text { Initial follow-up CT at } 6 \text { - } 12 \text { months; } \\
\text { then at } 18 \text { - } 24 \text { months if no change }\end{array}$ \\
\hline$>6-8 \mathrm{~mm}$ & $\begin{array}{l}\text { Initial follow-up CT at } 6 \text { - } \\
12 \text { months; then at } 18-24 \\
\text { months if no change }\end{array}$ & $\begin{array}{l}\text { Initial follow-up CT at } 3-6 \text { months; } \\
\text { then at } 9 \text { - } 12 \text { months and } 24 \\
\text { months if no change }\end{array}$ \\
\hline \multirow[t]{3}{*}{$>8 \mathrm{~mm}$} & $\begin{array}{l}\text { Follow-up CT at } 3,9 \text { and } 24 \\
\text { months }\end{array}$ & Same as low risk \\
\hline & \multicolumn{2}{|l|}{ Dynamic contrast-enhanced CT } \\
\hline & \multicolumn{2}{|l|}{ Consider PET-CT and/or biopsy } \\
\hline \multicolumn{3}{|l|}{$\begin{array}{l}\text { Subsolid nodules } \\
\text { (pGGNs) }\end{array}$} \\
\hline$<5 \mathrm{~mm}$ & \multicolumn{2}{|l|}{ No follow-up needed } \\
\hline$\geq 5 \mathrm{~mm}$ & \multicolumn{2}{|c|}{$\begin{array}{l}\text { Initial follow-up at } 3 \text { months; if persistent, annual CT for } \geq 3 \text { years (FDG- } \\
\text { PET of limited value, potentially misleading and not recommended) }\end{array}$} \\
\hline \multicolumn{3}{|l|}{$\begin{array}{l}\text { Subsolid nodules } \\
\text { (partly solid nodules) }\end{array}$} \\
\hline$<5 \mathrm{~mm}$ & \multicolumn{2}{|c|}{ Initial follow-up at 3 months; if persistent, annual CT for $\geq 3$ years } \\
\hline$\geq 5 \mathrm{~mm}$ & \multicolumn{2}{|c|}{$\begin{array}{l}\text { Initial follow-up at } 3 \text { months; if persistent, biopsy or surgical } \\
\text { resection (consider PET-CT for partly solid nodules with a solid } \\
\text { component }>8 \mathrm{~mm} \text { ) }\end{array}$} \\
\hline
\end{tabular}

however, also incorporates surgical risk in their management algorithm. The new BTS guideline is based on a comprehensive review of the current literature and includes nodule volume and VDT in addition to nodule size. ${ }^{[4]}$ Management options include serial CT surveillance, further imaging, non-surgical biopsy and surgical resection.

Decisions about further evaluation depend on clinical probability of malignancy determined by clinical, radiological and various logistic models, nodule characteristics such as size, attenuation (solid v. subsolid) and growth (VDT), as well as informed patient preference, associated risks and comorbidities that influence fitness for surgery.

The current BTS guideline recommends that the same diagnostic approach be applied to nodules that are discovered incidentally, via screening studies, in patients with a history of extrapulmonary malignancy, and in those with known lung malignancy. No consensus was reached on the risk of malignancy in SPNs in patients with a previous history of malignancy, with some studies indicating an increased risk and others showing no difference. ${ }^{[36-39]}$ Lung nodules detected in patients considered for radical cure should be evaluated on their own and not assumed to be malignant, as the probability of these being benign is high.

The BTS 2015 guideline addresses four groups of patients: $(i)$ requiring no further follow-up; (ii) with solid nodules $\geq 5$ $<8 \mathrm{~mm}$ in diameter or volume $<300 \mathrm{~m}^{3}$; (iii) with solid nodules with diameter $\geq 8 \mathrm{~mm}$ or volume $\geq 300 \mathrm{~m}^{3}$; and (iv) with subsolid nodules.

\section{No further follow-up}

No follow-up is required in patients with solid nodules with benign patterns of calcification, nodule size $<5 \mathrm{~mm}$ (both solid and subsolid) or a volume $<80 \mathrm{~mm}^{3}$, and solid perifissural or subpleural nodules $<10 \mathrm{~mm}$ with triangular or lentiform shape. However, caution and follow-up are advised for perifissural nodules $>10 \mathrm{~mm}$, especially in patients with a history of extrapulmonary cancer. ${ }^{[4]}$

Lung screening studies have provided evidence that nodules $<5 \mathrm{~mm}$ or $<100 \mathrm{~mm}^{3}$ have a low risk of malignancy, i.e. there is no 
difference compared with individuals without pulmonary nodules. ${ }^{[24]}$ However, because of lack of standardisation between volumetric determining programmes, the BTS has reduced the threshold value to $80 \mathrm{~mm}^{3}$. Studies of patients with perifissural nodes $<10 \mathrm{~mm}$ showed that none of the nodules was malignant. ${ }^{[18]}$

\section{Solid nodules $\geq 5-<8 \mathrm{~mm}$ in diameter or volume $\geq 80-<300 \mathrm{~mm}^{3}$}

The risk of malignancy in this group was found to be low $(2.4 \%)$ in the NELSON trial, justifying conservative management with $\mathrm{CT}$ surveillance.

\section{Solid nodules $\geq 5-<8 \mathrm{~mm}$ in diameter or volume $\geq 300 \mathrm{~m}^{3}$}

The NELSON trial found an increased risk of $16.9 \%$ for malignancy in nodules with a volume $\geq 300 \mathrm{~mm}^{3}$, and $9.7 \%$ for lung nodules with a diameter $>8 \mathrm{~mm}$ (Fig. 5). ${ }^{[24]}$

In this group of patients with nodule size $\geq 8 \mathrm{~mm}$ and volume $\geq 300 \mathrm{~m}^{3}$, the BTS recommendations include risk stratification using the Brock model. If the risk is low $(<10 \%)$, serial CT follow-up is recommended, and if the risk is deemed to be high ( $>10 \%)$, further imaging with PET$\mathrm{CT}$ is indicated. Additional risk stratification is then suggested with the use of the Herder model.

Using the Herder risk stratification model, suggestions are as follows: $(i)$ low risk $(<10 \%)$ - can be followed-up by CT surveillance; (ii) intermediate risk (10 - 70\%) - further evaluation such as non-surgical biopsy, excision biopsy or CT surveillance should be based on patient preference and associated comorbidities; and (iii) high risk (>70\%) - surgical biopsy is the best option, with non-surgical treatment for those who are poor surgical candidates.

In facilities where volumetric measurement can be done, follow-up of patients with solid nodules with interval CT and determination of VDT at 1 year for nodules $5-6 \mathrm{~mm}$, and at 3 months and 1 year for nodules with diameter $\geq 6 \mathrm{~mm}$ and volume $\geq 80 \mathrm{~mm}^{3}$, is suggested. A volume change of $\geq 25 \%$ is defined as significant growth and requires further intervention (imaging, biopsy or surgery). Patients can be discharged if the volume change is $<25 \%$ at 1 year, although if diameter is used to assess growth a 2 -year follow-up

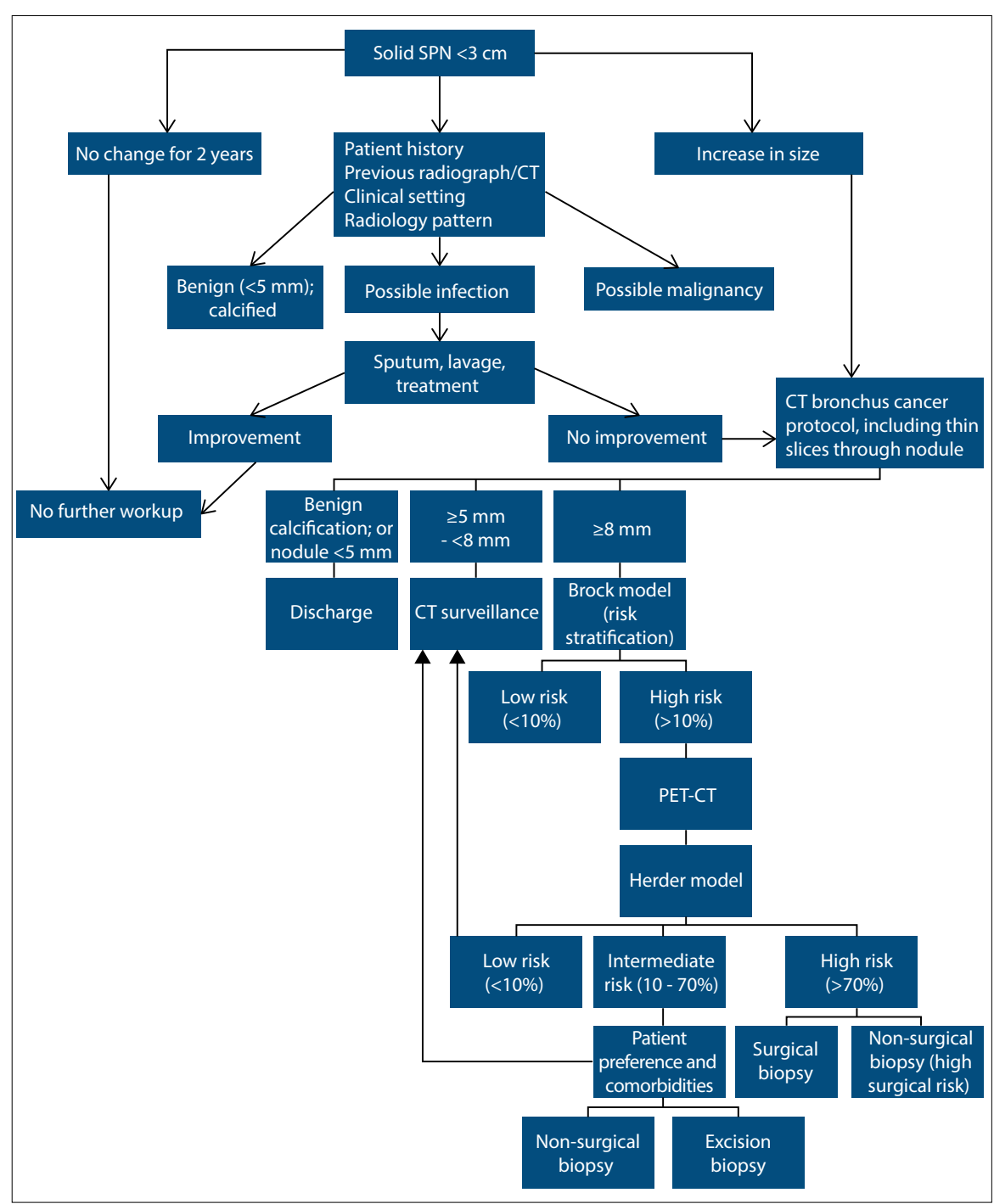

Fig. 5. A suggested approach to SPNs (adapted from BTS and Murrmann et al. ${ }^{[40]}$ ).

is required. A patient with VDT $>600$ days could be discharged or CT surveillance could be done based on patient preference. A VDT 400 - 600 days should prompt a biopsy or surveillance based on patient preference, whereas a VDT $<400$ days should definitely indicate further workup and management.

\section{Subsolid nodules}

Subsolid nodules may represent slowgrowing indolent tumours and further management will be dependent on size, risk stratification in persistent nodules, growth and nodule subtype. For nodules $\geq 5 \mathrm{~mm}$, a repeat CT scan is advised in 3 months. If the nodule disappears, the patient may be discharged. CT surveillance with intervals of 1,2 and 4 years is suggested for patients with low risk $(<10 \%)$. CT surveillance, CT-guided biopsy, or resection should be considered in patients with a high risk (>10\%), taking into account patient preference and surgical risk. Resection/non-surgical treatment or observation should be considered for pGGNs that enlarge $\geq 2 \mathrm{~mm}$, considering patient preference and surgical risk. If observation is chosen, a repeat $\mathrm{CT}$ at a maximum interval of 6 months should be performed. Resection/ non-surgical treatment should be considered for patients with partly solid nodules that show an increase in solid component, pGGNs that develop a solid component, and pathologically proven malignancy, keeping in mind patient preference and surgical risk.

\section{Biopsy}

Non-surgical biopsy

Options for non-surgical biopsy include bronchoscopy and CT-guided transthoracic 
needle aspiration (TTNA) or biopsy. The sensitivity of CT-TTNA was $90 \%$ in 11 studies, with the risk of pneumothorax between $4 \%$ and $8 \%{ }^{[20]}$ Conventional bronchoscopy has a low yield and a low sensitivity of $13.5 \%$ reported in the NELSON study and is not recommended by the current BTS guideline. ${ }^{[4,24]}$ Bronchoscopy yield can be augmented with fluoroscopy, radial endobronchial ultrasound and electromagnetic navigation bronchoscopy and is indicated if a bronchus sign is seen on CT.

\section{Surgical biopsy}

Surgical resection is the gold standard and the definitive treatment for malignant nodules. Surgical approaches include video-assisted thoracoscopic surgery (VATS) or thoracotomy. Patients fit for surgery should undergo VATS wedge resection with progression to lobectomy and systematic sampling of mediastinal lymph nodes, if malignant. Sublobar resection (wedge resection and segmentectomy) was associated with worse outcomes in cases of stage 1 cancer. ${ }^{[41]}$ Segmentectomy may be considered in patients in whom preservation of lung tissue will improve outcome. In patients who are not candidates for surgery, therapeutic alternatives include external beam radiation therapy and percutaneous radiofrequency ablation. ${ }^{[4]}$

\section{SPN in the SA context}

The World Health Organization (WHO) has rated SA as a highprevalence (>125/100 000) TB region, with statistics suggesting an estimated incidence of 450000 active cases of TB in 2013. The incidence of benign granulomas is therefore exceedingly high, with incidental upper-lobe nodules being a common finding on imaging. In this setting, these findings would raise an already very high false-positive rate even further. This could lead to unnecessary investigations, high cost and associated morbidity. Even with the use of FDG-PET, the high false-positive rate would still limit accuracy, further complicating the evaluation of SPNs in our setting. ${ }^{[30]}$

\section{Conclusion}

The SPN remains a clinical challenge, with the potential of early malignancy. The 2015 BTS guideline assists with risk stratification and appropriate management of different patient groups. Benign granulomas in a high TB-endemic area such as SA can complicate the evaluation of SPNs. Risk stratification models and management algorithms need to be validated in this setting.

\section{References}

1. Detterbeck FC, Boffa DJ, Tanoue LT. The new lung cancer staging system. Chest 2009;136(1):260-271. DOI:10.1378/chest.08-0978

2. Ost DE, Gould MK. Decision making in patients with pulmonary nodules. Am J Respir Crit Care Med 2012;185(4):363-372. DOI:10.1164/rccm.201104-0679CI

3. Ost D, Fein AM, Feinsilver SH. The solitary pulmonary nodule. N Engl J Med 2003;348(25):2535-2542. DOI:10.1056/NEJMcp012290

4. British Thoracic Society. The British Thoracic Society guideline for the investigation and management of pulmonary nodules. Thorax 2015;70:ii1-ii54. DOI:10.1136/ thoraxjnl-2015-207168

5. Gould MK, Tang T, Liu ILA, et al. Recent trends in the identification of incidental pulmonary nodules. Am J Respir Crit Care Med 2015;192(10):1208-1214. DOI:10.1164/rccm.201505-0990OC

6. Swensen SJ, Silverstein MD, Ilstrup DM, Schleck CD, Edell ES. The probability of malignancy in solitary pulmonary nodules. Application to small radiologically indeterminate nodules. Arch Intern Med 1997;157(8):849-855. DOI:10.1001/ archinte.157.8.849
7. McWilliams A, Tammemagi MC, Mayo JR, et al. Probability of cancer in pulmonary nodules detected on first screening CT. N Engl J Med 2013;369(10):910-919. DOI:10.1056/NEJMoa1214726

8. Swensen SJ, Jett JR, Hartman TE, et al. CT screening for lung cancer: Fiveyear prospective experience. Radiology 2005;235(1):259-265. DOI:10.1148/ radiol.2351041662

9. Diederich S, Wormanns D, Semik M, et al. Screening for early lung cancer with lowdose spiral CT: Prevalence in 817 asymptomatic smokers. Radiology 2002;222(3):773781. DOI:10.1148/radiol.2223010490

10. Aberle DR, Adams AM, Berg CD, The National Lung Screening Trial Research team. Reduced lung-cancer mortality with low-dose computed tomographic screening. N Engl J Med 2011;365(5):395-409. DOI:10.1056/nejmoa1102873

11. Gould MK, Ananth L, Barnett PG. A clinical model to estimate the pretest probability of lung cancer in patients with solitary pulmonary nodules. Chest 2007;131(2):383388. DOI:10.1378/chest.06-1261

12. Cummings SR, Lillington GA, Richard RJ. Estimating the probability of malignancy in solitary pulmonary nodules. A Bayesian approach. Am Rev Respir Dis 1986;134(3):449-452. DOI:10.1164/arrd.1986.134.3.449

13. Gurney JW, Lyddon DM, McKay JA. Determining the likelihood of malignancy in solitary pulmonary nodules with Bayesian analysis. Part II. Application. Radiology 1993;186(2):415-422. DOI:10.1148/radiology.186.2.8421744

14. Khan AN, Al-Jahdali HH, Allen CM, Irion KL, Al Ghanem S, Koteyar SS. The calcified lung nodule: What does it mean? Ann Thorac Med 2010;5(2):67-79. DOI:10.4103/1817-1737.62469

15. Erasmus JJ, Connolly JE, McAdams HP, Roggli VL. Solitary pulmonary nodules: Part I. Morphologic evaluation for differentiation of benign and malignant lesions. Radiographics 2016;20(1):43-58. DOI:10.1148/radiographics.20.1.g00ja0343

16. Gould MK, Donington J, Lynch WR, et al. Evaluation of individuals with pulmonary nodules: When is it lung cancer? Diagnosis and management of lung cancer. American College of Chest Physicians evidence-based clinical practice guidelines. Chest 2013;143(5 Suppl):93-120. DOI:10.1378/chest.12-2351

17. Grewal RG, Austin JH. CT demonstration of calcification in carcinoma of the lung. J Comput Assist Tomogr 1994;18(6):867-871.

18. De Hoop B, van Ginneken B, Gietema H, Prokop M. Pulmonary perifissural nodules on CT scans: Rapid growth is not a predictor of malignancy. Radiology 2012;265(2):611-616. DOI:10.1148/radiol.12112351

19. Winer-Muram HT. The solitary pulmonary nodule. Radiology 2006;239(1):34-49. DOI:10.1148/radiol.2391050343

20. Wahidi MM, Govert JA, Goudar RK, Gould MK, McCrory DC. Evidence for the treatment of patients with pulmonary nodules: When is it lung cancer? Chest 2007;132(3 Suppl):94S-107S. DOI:10.1378/chest.07-1352

21. Garland LH, Coulson W, Wollin E. The rate of growth and apparent duration of untreated primary bronchial carcinoma. Cancer 1963;16:694-707. DOI:10.1002/10970142(196306)16:6<694::AID-CNCR2820160603>3.0.CO;2-J

22. Collins VP, Loeffler RK, Tivey H. Observations on growth rates of human tumors. Am J Roentgenol Radium Ther Nucl Med 1956;76(5):988-1000.

23. Nathan MH, Collins VP, Adams RA. Differentiation of benign and malignant pulmonary nodules by growth rate. Radiology 1962;79:221-232. DOI:10.1148/79.2.221

24. Zhao YR, Xie X, de Koning HJ, Mali WP, Vliegenthart R, Oudkerk M. NELSON lung cancer screening study. Cancer Imaging 2011;11(1A):79-84. DOI:10.1102/14707330.2011 .9020

25. Woodring JH, Fried AM, Chuang VP. Solitary cavities of the lung: Diagnostic implications of cavity wall thickness. AJR Am J Roentgenol 1980;135(6):1269-1271.

26. Woodring JH, Fried AM. Significance of wall thickness in solitary cavities of the lung: A follow-up study. AJR Am J Roentgenol 1983;140(3):473-474. DOI:10.2214/ ajr.135.6.1269

27. Gill RR, Matsusoka S, Hatabu H. Cavities in the lung in oncology patients: Imaging overview and differential diagnoses. Appl Radiol J Pract Imaging Manag 2010;39(6):10-21.

28. Herder GJ, van Tinteren H, Golding RP, et al. Clinical prediction model to characterize pulmonary nodules: Validation and added value of $18 \mathrm{~F}$-fluorodeoxyglucose positron emission tomography. Chest 2005;128(4):2490-2496. DOI:10.1378/chest.128.4.2490

29. Cronin P, Dwamena BA, Kelly AM, Carlos RC. Solitary pulmonary nodules: Meta-analytic comparison of cross-sectional imaging modalities for diagnosis of malignancy. Radiology 2008;246(3):772-782. DOI:10.1148/radiol.2463062148

30. Du Toit R, Shaw JA, Irusen EM, von Groote-Bidlingmaier F, Warwick JM, Koegelenberg CFN. The diagnostic accuracy of integrated positron emission tomography/computed tomography in the evaluation of pulmonary mass lesions in a tuberculosis-endemic area. S Afr Med J 2015;105(12):1049-1052. DOI:10.7196/SAMJ.2015.v105i12.10300

31. Deppen S, Putnam JB, Andrade G, et al. Accuracy of FDG-PET to diagnose lung cancer in a region of endemic granulomatous disease. Ann Thorac Surg 2011;92(2):428-432. DOI:10.1016/j.athoracsur.2011.02.052 
32. Sathekge MM, Maes A, Pottel H, Stoltz A, van der Wiele C. Dual time-point FDG $\mathrm{PET} / \mathrm{CT}$ for differentiating benign from malignant solitary pulmonary nodules in a TB endemic area. S Afr Med J 2010;100(9):598-601. DOI:10.7196/samj.4082

33. Nomori H, Watanabe K, Ohtsuka T, Naruke T, Suemasu K, Uno K. Evaluation of F-18 fluorodeoxyglucose (FDG) PET scanning for pulmonary nodules less than $3 \mathrm{~cm}$ in diameter, with special reference to the CT images. Lung Cancer 2004;45(1):19-27. DOI:10.1016/j.lungcan.2004.01.009

34. MacMahon H, Austin JHM, Gamsu G, et al. Guidelines for management of small pulmonary nodules detected on CT scans: A statement from the Fleischner Society. Radiology 2005;237(2):395-400. DOI:10.1148/radiol.2372041887

35. Naidich DP. Recommendations for the management of subsolid pulmonary nodules detected at CT: A statement from the Fleischner Society. Radiology 2013;266(1):304317. DOI:10.1148/radiol.12120628

36. Quint LE, Park CH, Iannettoni MD. Solitary pulmonary nodules in patients with extrapulmonary neoplasms. Radiology 2000;217(1):257-261. DOI:10.1148/ radiology.217.1.r00oc20257
37. Khokhar S, Vickers A, Moore MS, Mironov S, Stover DE, Feinstein MB. Significance of non-calcified pulmonary nodules in patients with extrapulmonary cancers. Thorax 2006;61(4):331-336. DOI:10.1136/thx.2005.051508

38. Mery CM, Pappas AN, Bueno R, et al. Relationship between a history of antecedent cancer and the probability of malignancy for a solitary pulmonary nodule. Chest 2004;125(6):2175-2181. DOI:10.1378/chest.125.6.2175

39. Hanamiya M, Aoki T, Yamashita Y, Kawanami S, Korogi Y. Frequency and significance of pulmonary nodules on thin-section CT in patients with extrapulmonary malignant neoplasms. Eur J Radiol 2012;81(1):152-157. DOI:10.1016/j.ejrad.2010.08.013

40. Murrmann GB, van Vollenhoven FHM, Moodley L. Approach to a solid solitary pulmonary nodule in two different settings: 'Common is common, rare is rare' J Thorac Dis 2014;6(3):237-248. DOI:10.3978/j.issn.2072-1439.2013.11.13

41. Ginsberg RJ, Rubinstein LV. Randomized trial of lobectomy versus limited resection for T1 N0 non-small cell lung cancer. Ann Thorac Surg 1995;60(3):615-622. DOI:10.1016/0169-5002(96)85902-2 